\title{
PROJECTING OF URBAN TRANSPORT INFRASTRUCTURE CONSIDERING THE HUMAN FACTOR
}

Projecting of urban transport infrastructure, which forms a comfortable habitat and development of territories, is impossible without forecasting the parameters of transport and passenger flows. These parameters are formed under the influence of the subjective choice of urban residents on the routes along the road and route network. The study aims to identify factors affecting the distribution of transport and passenger flows through the existing urban transport network. It is revealed that the gravity function of employees of city-forming enterprises, which determines the emergence and absorption of transport and passenger flows of the city districts, can be described by parameters of urban structure, socio-economic factors and parameters that characterize zones of residence and main area of employment. The developed model was tested on real data from Kharkov - the second largest city in Ukraine.

Keywords: infrastructure, transport and passenger flows, the gravity function, transit, mobility

\section{Introduction}

Transport and transport infrastructure have a significant impact on the economic development of cities, the main area of employment, productivity of people, the cost indicators of the transport process. This is largely due to the geographical situation, the structure of the street-road network, the patterns of settlement and various scenarios of economic development. The growth of the level of motorization causes the need to develop a street-road network, increase the throughput and carrying capacity of the urban transport system.

\section{Analysis of recent research and publications}

The urban transport sector is economically sustainable when resources are efficiently used and allocated to maximize benefits and minimize external mobility costs [1] Urban residential zones, in which live more than half the world's population, are facing unprecedented challenges in the field of transport and mobility. [2]. In the context of globalization and a significant increase in the level of motorization, one of the tasks in the development of transport infrastructure is forecasting the parameters of transport and passenger flows while improving the transport provision of new residential districts and various urban objects. Moreover, it is often necessary to assess the impact of the designed object on the transport infrastructure. Thus, the solution of problems of the formation and development of transport infrastructure requires consideration of a large number of factors related to the indicators of the technical development of the city [3]. Determining the directions of the development of transport infrastructure, the implementation of which will lead to a sustainable transport system, is a serious problem, as it is associated with a high degree of uncertainty about the future impact of the proposed measures on the transport system and urban environment [4].

Researchers identify four levels of transport planning: object, sectoral, integrated transport, relating to the transport system of the city, and urban, containing the complex of relations between the city and transport [5]. A well-functioning transport infrastructure ensures the sustainability and availability of transport for the population; the possibility of free transit in the zone and increasing mobility; creates the conditions for the development of the system of settlement, employment, recreation [6]. This requires a balance and coordination of land use, building and development of transport infrastructure. Such coordination is necessary and possible not only at the planning stage of new development zones. It should be carried out in the course of any major projects of urban territorial development [7]. The prerequisite for a smart city is that, having the right information at the right time, citizens, service providers and municipal authorities will be able to make more correct decisions that will lead to an improvement in the quality of life of the inhabitants and the overall sustainability of the city [8]. This should be one of the directions of state policy in which planning decisions

\footnotetext{
Natalia Davidich ${ }^{1}$, Andrii Galkin $^{2, *}$, Vladimir Sabadash ${ }^{3}$, Igor Chumachenko $^{1}$, Tatyana Melenchuk ${ }^{4}$, Yurii Davidich ${ }^{2}$ ${ }^{1}$ Department of Project Management in Municipal Services and Construction, O. M. Beketov National University of Urban Economy in Kharkiv, Ukraine

${ }^{2}$ Department of Transport System and Logistics, O. M. Beketov National University of Urban Economy in Kharkiv, Ukraine ${ }^{3}$ Kharkiv Research Institute of Forensic Examinations Hon. Prof. M. S. Bokarius, Ukraine

${ }^{4}$ Odessa State Academy of Technical Regulation and Quality, Ukraine

*E-mail of corresponding author: galkin.tsl@gmail.com
} 
regarding the development of cities must be coordinated with the development of transport [9].

The constant increase in the number of cars makes it necessary to optimize the road network so as to satisfy most of the needs of the city. To reduce the risk of investment to a minimum, it is necessary to take into account the patterns of development of the system of roads, the distribution of the load on its individual sections. Therefore, modelling and optimal planning of the transport network takes on particular importance [10]. At the same time, the current problem of road congestion for the largest cities is one of the central ones that requires urgent attention [5].

The most important and fundamental feature of the formation of the loading of a transport network is that the choice of means and ways of travel users of the network affects the same choice that is being made by other users. This circumstance creates a feedback in the process of forming the loading of a transport network. The choice is based on a comparison of the parameters of different ways, while the parameters themselves are determined by the load on the transport network. At the same time, there is some uncertainty in predicting the routes by drivers. [11]. The state of flows is generated by the mutual transit of vehicles that implement the well-known OD matrix [12].

According to the researchers, if the flows in the network are in an equilibrium state, then the parameters of all the used ways connecting the two districts are in such a state as well. Formation of transport and passenger flows can be described by the gravity function, which determines the probability of choosing to travel to the zone $j$ by population that leaves the zone $i$. The gravity function may include parameters characterizing the arrival and departure zones, as well as parameters characterizing the availability of alternative travel options (e.g., public transport). To form a origin-destination matrix, the gravitational modeling approach can be used. [13]. In this case, the formation of the mobility of the population is mainly influenced by the social composition of the population and the target nature of mobility [14]. Existing at present gravity functions are offered for all inhabitants of cities irrespective of social composition of urban population and as a parameter have only transit time [15]. The difference is only the type of function used. Some researchers describe it by hyperbolic dependence [15]. Others use the exponential model [16]. The third, according to the materials of the personal data, conclude that the best approximation of the gravity function is the function of the EVA [17].

In fact, residents belonging to different groups of the population have different priorities when choosing zones of gravity [15]. Researchers identify the following independent groups of population: employees of city-forming enterprises; employees of city service enterprises; students of higher educational institutions, colleges, secondary vocational schools. As a result, the gravity function should be formed separately for each group of active urban populations. In this case, in all processes in which a person is involved, there is an individual and collective behavior of people [18].
The purpose of users of the network may be to minimize travel-related losses, such as travel time, expenses of nervous energy and maximize their safety with the slightest deviation from comfortable conditions when traveling along several routes [19]. An adequate description of human behavior in practice is needed [20]. In this case, a combination of technological efficiency and behavioral changes is advisable [9].

A large role on the parameters of travel have individual qualities of a person [21]. The researchers propose to combine individual characteristics of people with the same properties of the central nervous system. In their opinion, the properties of nervous processes form certain combinations that determine the type of the nervous system or the type of higher nervous activity [22]. Thus, we can conclude that the individual characteristics of urban residents, which are determined by the type of nervous system, significantly affect the choice of mobility parameters and the choice of the route.

\section{Research problem and purpose statement}

The conducted researches aimed to determine the regularities of changing the gravity function of workers of city-forming enterprises for the projecting of urban transport infrastructure taking into account the human factor.

To achieve this goal, the following tasks were solved:

- identification of factors influencing the patterns of distribution of transport and passenger flows through the transport network;

- $\quad$ analysis of the influence of the parameters of the city structure, socio-economic factors and factors that characterize the zones of residence and employment on the change of the gravity function between the urban districts.

\section{Data and results of research}

\subsection{Mathematical model}

The projecting of transport infrastructure should be based on the results of a study of the patterns of influence of urban parameters on the distribution of transport and passenger traffic along the road network. Formation of flows occurs on the basis of the dispersal of urban residents, which determines the gravity function of the city districts. The amount of transport and passenger traffic flows transit is complemented by the visiting population. Adequate gravity functions should take into account not only time of travel, as at present, but also a more complex dependence, which includes other parameters influencing the choice of population of places of gravity.

The gravity function of inter-zone work-related mobility can be formalized as follows: 


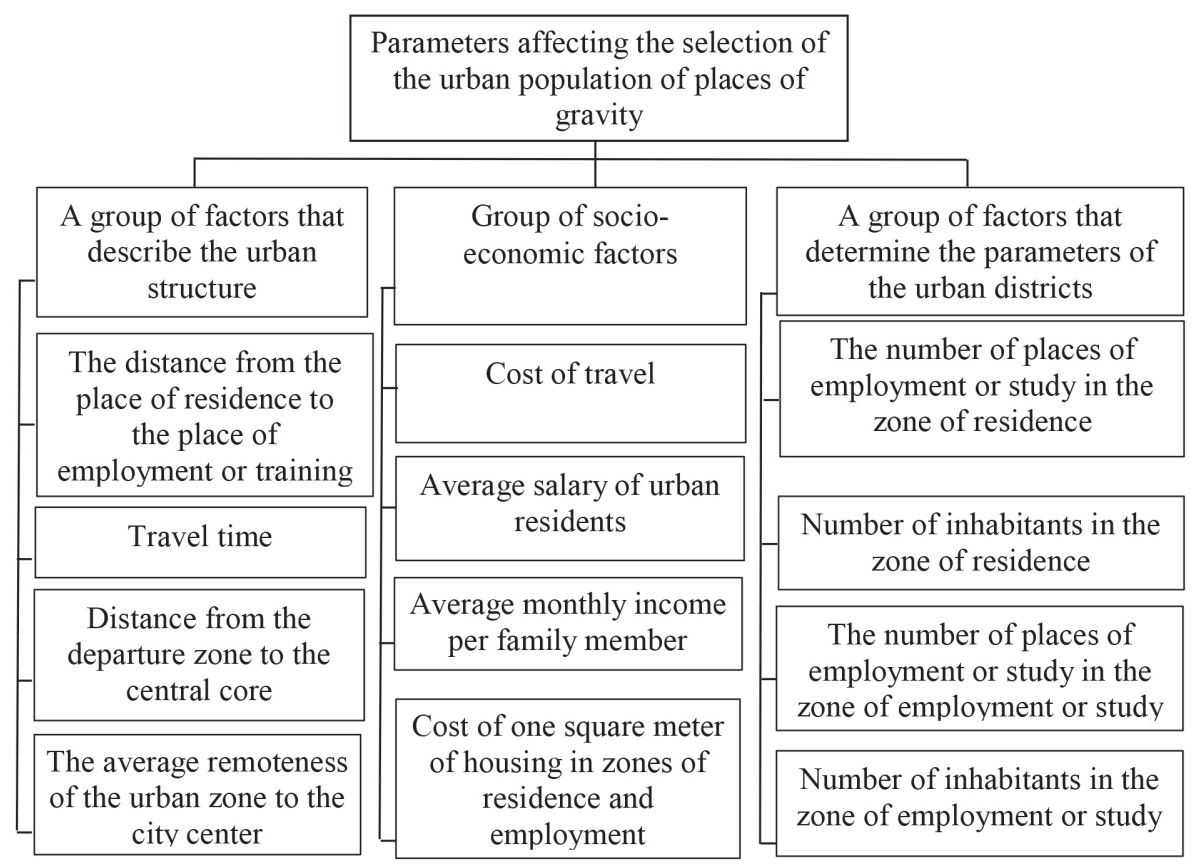

Figure 1 Parameters affecting the selection of the urban population of places of gravity

$d^{m t}{ }_{i j}=f(G, S, R)$

where:

$d^{m t}{ }_{i j}$ - the gravity function of inter-zone labor transit between ( $m t$ ) the $i$ - th zone of departure and the $j$-th zone of arrival, $G$ - group of factors that describe the urban structure,

$S$ - group of socio-economic factors and data,

$R$ - group of factors determining the urban zones.

It is possible to identify the following factors of each group (Figure 1).

The factors that describe the structure of the city, characterize the features of the organizational structure of the road network and the trip distance around the city.. The distance from the residence to the work and the traveling time directly reflect the difficulty of communication between the transport zones. The distance from the origin zone to the city core and the average distance from the residence to the city core characterize the organizational structure of the urban road network and the distance.

The factors that determine the parameters of the city's zones reflect the essence of the gravity function of the fact that people move from places of residence in which the number of workplaces or places of study is less than the number of workplaces or places of study in other zones.

Socio-economic factors estimate the costs for transit of urban residents and the expediency of changing their place of residence in relation to the place of work or study.

Travel costs indicate the difficulty of travelling in terms of financial loss. The average wage estimates the financial capacity of the population, which has a direct impact on the travel quantity and the choice of the route. The average monthly income per household member reflects the financial security of urban residents. It also depends on the choice of transport and the possibility of changing the place of residence relative to the place of work. The cost of one square meter of housing in the area of residence and the cost of one square meter of housing in the area of employment reflect the ability to change a place of residence relative to the place of work or study, that is, whether an employee can buy housing in the place of work in terms of their financial capacity, and vice versa to change the place of work. All socio-economic factors should be considered in relation to the value of the average wage in the research region.

Using the method of expert assessments, the general type of gravity function for intra-zone travel not connected with work was determined:

$$
\begin{aligned}
& d_{j z}^{b k}=a 1 \cdot \exp \left(1-\frac{\Theta_{z}}{\Theta}\right)+a 2 \cdot \exp \left(\frac{L_{j z}}{\bar{L}}\right)+ \\
& +a 3 \cdot\left(\frac{N_{j}}{\bar{N}}\right)+a 4 \cdot \log \left(\frac{\delta_{j z}}{\delta}\right)+a 5 \cdot \log \left(\frac{R_{j z}}{\bar{R}}\right)+ \\
& +a 6 \cdot \log \left(\frac{S_{z}}{S}\right)
\end{aligned}
$$

where:

$d^{b k}{ }_{j z}$ - the gravity function between the $j$-th zones of departure and the $z$-th store for intra-zone cultural and social mobility (bk),

$\Theta_{z}, \bar{\Theta}$ - respectively, the value parameters of gravity that characterize the store $z$, and the average cost parameters of the gravity of stores in all zones, UAH,

$L_{j z}, \bar{L}$ - respectively, the distance from the $j$-th zone to the $z$-th trade establishment and the average distance from the zone to stores in the all zones, $\mathrm{km}$,

$N_{j}, \bar{N}$ - respectively, the number of consumers in the $j$-th zone and the average number of consumers in all zones, ppl., 
$\delta_{j z}, \bar{\delta}$ - respectively, the slope factor ratio of the locality when moving from the $j$-th zone to the $z$-th store and the average slope factor in the all zones,

$R_{j z}, \bar{R}$ - respectively, the non-linearity factor of the connection when moving from the $j$-th microdistrict to the $z$-th trade establishment and the average non-linearity factor of the connection in all zones,

$S_{z}, \bar{S}$ - respectively, the trade service dimension in the $z$-th store and the average zone of trade service institutions in all zones, $\mathrm{m}^{2}$,

$a 1, a 2, a 3, a 4, a 5, a 6$ - calibration coefficients, the value of which depends on the parameters of microdistricts and trading establishments.

The direction of influence of each factor was determined by analyzing its essence in relation to the function of attraction. The use of gravity functions that take into account the above-mentioned factors will allow to receive a matrix of correspondence of the urban population. This matrix can be used to model transport and passenger flows, considering the projected parameters of the urban infrastructure.

\subsection{Data of instance}

In order to realize the dependence (1), the definition of the gravity function of employees of city-forming enterprises of Kharkiv city was carried out. Kharkiv is the regional center of Ukraine and the second largest after Kiev. Currently, the urban population is about 1.5 million people. The total area of Kharkiv is now 35002.26 ha. The length of the backbone network of the city (citywide streets, streets of the regional significance and highways) is $391.2 \mathrm{~km}$, and the average population density is 47.9 people per ha.

Kharkiv is one of the largest transport hubs of Ukraine (railways and highways, international airport). The city has an extensive network of street public transport: metro, route taxis, buses, trolley buses, trams. The total length of the Kharkiv metro lines is $33 \mathrm{~km}$, the number of stations is 26 . There are 18 tram, 29 trolleybus and 48 bus routes organized in the city. The fare in the city electric transport is $\$ 0.19$, subway $\$ 0.27$, buses $\$ 0.37$. The average wage is $\$ 285$. The total fleet of individual cars is 196.8 thousand cars. The level of automobilization is 134.8 cars per 1000 inhabitants.

In order to obtain the initial data needed to determine the gravity function between the place of employment and residence, field surveys were carried out. The study was conducted by a questionnaire method among workers of city-forming enterprises of the city of Kharkiv (Figure 2). The possibility of using a large sample survey to identify data on the preferences of urban dwellers has previously been substantiated. [23]. Employees of 58 city-forming enterprises located in various urban zones took part in the survey. During the survey, the places of employment and residence of employees were recorded, the type of mobility (transit), its temporary indicators, types of transport, price of transit and average monthly income per family member were determined. The total number of respondents was 874 people. Processing the questionnaires was to identify zones of departure and arrival. These zones were formed in accordance with the places of residence of workers and their place of employment. To solve this problem, a topological map of the city of Kharkiv was developed, consisting of 63 transport hubs and 100 connections. Using this scheme, the average distance of the districts from the geographical center of the city and the distance to the zone of employment was determined. The average travel time was defined as the sum of transport element's time from the place of residence to the place of employment or training: walking to stopping point, waiting for a vehicle, time to transfer from one mode of transport to another, walking time from the final stop to place of employment. The average cost of transit was also determined. For calculations for each zone of the urban housing prices were determined as well as the number of residents and places of employment in the zones of residence and work.

At the next stage the following data were determined: the significance of the gravity function of city-forming enterprises between zones $i$ and $j\left(d^{y}{ }_{i j}\right)$, the distance between zones $i$ and $j\left(l_{i j}, \mathrm{~km}\right)$, the travel time between zones $i$ and $j\left(t_{i j}\right.$, min), the ratio of the travel cost between zones to the average salary in the city of Kharkiv $\left(S_{i j} / Z s r\right)$, the ratio of the distance from the departure zone $i$ to the central core to the average distance from the urban zone to the center $(\mathrm{Lr} / \mathrm{Lrs})$, the ratio of income of a resident to the average wage in the Kharkiv $(D / Z s r)$, the ratio of the cost of one square meter of housing in the zone of residence $i$ to the average salary in the city of Kharkiv $\left(Z z_{i} / Z s r\right)$, the ratio of the cost of one square meter of housing in the industrial zone $j$ to the average salary $(Z r / Z s r)$, number of places of employment in the zone of residence ( $Q r . z_{i}$, units), the amount of residents in the zone ( $Q z . z_{i}$, ppl.), the amount of places of employment in the zone $j$ (Qr.r. units), the number of inhabitants in the inhabitans zone $j\left(Q z . r_{j}\right.$, ppl.). An example of the results of the calculation of the data is given in Table 1.

Thus, after conducting a field survey and processing its results, all the data needed to determine the gravity function between the employment zones and residence, depending on the factors that affect it, were obtained.

\subsection{Computer experiment}

The information obtained during the survey, makes it possible to carry out a mathematical description of the dependence of the change in the gravity function of the workers of the city-forming enterprises. For this purpose, the methods of correlation and regression analysis were used. The values of the regression coefficients were calculated using the least squares method. Model parameters were determined using appropriate statistical methods. A multifactor model of change of gravity function between the zones $i$ and $j$ was developed. The results of calculations of the parameters of the model of the change 


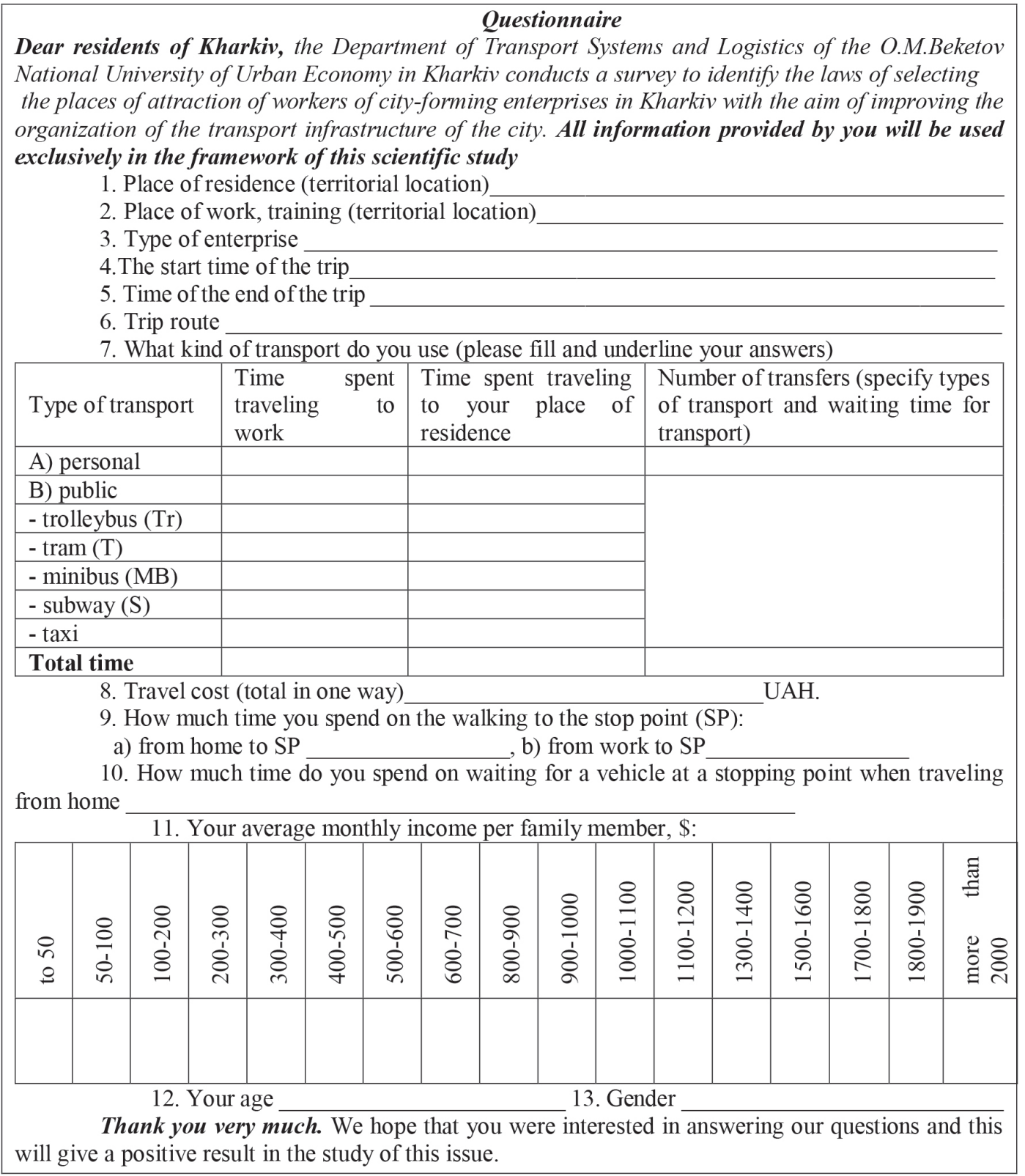

Figure 2 Questionnaire for workers of city-forming enterprises

Table 1 The results of the survey data calculation

\begin{tabular}{cccccccccccc}
\hline$d^{v}{ }_{i j}$ & $l_{i j}$ & $t^{v}{ }_{i j}$ & $\frac{S_{i j}}{Z s r}$ & $\frac{L_{r i}}{L_{r s}}$ & $\frac{D_{i}}{Z s r}$ & $\frac{Z z_{i}}{Z s r}$ & $\frac{Z r_{j}}{Z s r}$ & $Q r . z_{i}$ & $Q z . z_{i}$ & $Q r . r_{j}$ & $Q z . r_{j}$ \\
\hline 0.04 & 6.05 & 15 & 0.0012 & 1.13 & 0.67 & 2.79 & 3.77 & 8700 & 10205 & 30783 & 23463 \\
\hline 0.017 & 15.4 & 54 & 0.0018 & 1.24 & 1.72 & 3.59 & 3.81 & 8700 & 10205 & 17801 & 27552 \\
0.023 & 10.2 & 46 & 0.0013 & 1.07 & 1.14 & 4.23 & 3.13 & 18737 & 20992 & 31786 & 44432 \\
0.034 & 12 & 61 & 0.0016 & 1.05 & 1.33 & 3.38 & 2.54 & 21749 & 35278 & 25783 & 24453 \\
0.029 & 16 & 75 & 0.0019 & 1.13 & 1.78 & 3.38 & 3.76 & 13049 & 48107 & 34673 & 43567 \\
$\ldots$ & $\ldots$ & $\ldots$ & $\ldots$ & $\ldots$ & $\ldots$ & $\ldots$ & $\ldots$ & $\ldots$ & $\ldots$ & $\ldots$ & $\ldots$ \\
0.046 & 3.2 & 33 & 0.0011 & 1.25 & 0.35 & 4.49 & 2.73 & 12046 & 4082 & 23527 & 36534 \\
0.006 & 12.4 & 70 & 0.0013 & 1.08 & 1.38 & 3.88 & 3.78 & 3747 & 41547 & 32587 & 42566 \\
0.029 & 14 & 59 & 0.003 & 1.19 & 1.56 & 3.6 & 3.34 & 4216 & 44900 & 29837 & 41232 \\
0.017 & 20.1 & 90 & 0.0023 & 1.31 & 2.233 & 3.47 & 3.81 & 12046 & 6123 & 18865 & 25765 \\
0.003 & 7.2 & 17 & 0.0008 & 0.66 & 0.8 & 3.601 & 4.1 & 7027 & 19680 & 16532 & 22687 \\
\hline
\end{tabular}


Table 2 Limits of measurement of the model of change of the gravity function of employees of city-forming enterprises

\begin{tabular}{|c|c|c|}
\hline Indicator & $\begin{array}{l}\text { Designation, } \\
\text { dimension }\end{array}$ & $\begin{array}{l}\text { Measurement } \\
\text { boundaries }\end{array}$ \\
\hline Travel time between zones $i$ and $j$ & $t n_{i j}, \min$ & $9.5-100.1$ \\
\hline $\begin{array}{l}\text { The ratio of the distance from the departure zone } i \text { to the center to the average } \\
\text { distance from the zone to the city center }\end{array}$ & $\frac{L_{r_{i}}}{L_{r s}}$ & $0.39-2.44$ \\
\hline $\begin{array}{l}\text { The ratio of the cost of one square meter of housing in the zone of residence } i \text { to the } \\
\text { cost of one square meter of housing in the work zone } j\end{array}$ & $\frac{Z z_{i}}{Z r_{j}}$ & $0.726-1.21$ \\
\hline $\begin{array}{l}\text { The ratio of number of places of application of labor in the zone of work } i \text { to the } \\
\text { number of places of application of labor in the residence zone } j\end{array}$ & $\frac{Q r \cdot r_{i}}{Q r \cdot z_{j}}$ & $0.49-23$ \\
\hline $\begin{array}{l}\text { The ratio of the travel cost between zones } i \text { and } j \text { to the average income of a resident } \\
\text { of zone } i\end{array}$ & $\frac{S_{i j}}{D_{i}}$ & $0.0005-0.0092$ \\
\hline Quantity of inhabitants in the zone of residence $j$ & $Q z . z_{j}, \mathrm{ppl}$ & $3061-103794$ \\
\hline
\end{tabular}

Table 3 Characteristics of the model of change of the gravity function of employees of city-forming enterprises

\begin{tabular}{|c|c|c|c|c|}
\hline \multirow{2}{*}{ Factor } & \multirow{2}{*}{ Coefficient } & \multirow{2}{*}{ Standard error } & \multicolumn{2}{|c|}{ Student's t-test } \\
\hline & & & actual & calculated \\
\hline$\frac{1}{t n_{i j}}$ & 1.531 & 0.265 & 5.77 & 1.98 \\
\hline $1 /\left(\frac{L r_{i}}{L r s}\right)$ & 0.0212 & 0.009 & 2.27 & 1.98 \\
\hline $\log \left(\frac{Z z_{i}}{Z s r}\right)$ & -0.164 & 0.016 & -10.2 & 1.98 \\
\hline $\log \left(\frac{Q_{r \cdot r_{j}}}{Q_{r \cdot z i}}\right)$ & 0.043 & 0.004 & 11.45 & 1.98 \\
\hline$\sqrt{\left(\frac{S_{i j}}{Z s r}\right)}$ & -0.743 & 0.17 & -4.36 & 1.98 \\
\hline$Q_{z \cdot z i}^{1,2}$ & 0.000000027 & 0.000000013 & 2.06 & 1.98 \\
\hline
\end{tabular}

Table 4 Confidence intervals of the coefficients of the model

\begin{tabular}{ccc}
\hline Factor & Lower bound & Upper bound \\
\hline$\frac{1}{t n_{i j}}$ & 0.849 & 2.213 \\
$1 /\left(\frac{L r_{i}}{L r s}\right)$ & 0.0028 & 0.0452 \\
$\log \left(\frac{Z z_{i}}{Z s r}\right)$ & -0.205 & -0.123 \\
$\log \left(\frac{Q_{r \cdot r_{j}}}{Q_{r \cdot z i}}\right)$ & 0.034 & 0.053 \\
$\sqrt{\left(\frac{S_{i j}}{Z s r}\right)}$ & -1.181 & -0.304 \\
$Q_{z: z i}{ }^{1,2}$ & 0.0000000066 & 0.000000061
\end{tabular}

Qr.z $z_{\mathrm{i}}$ - number of places of application of labor in the zone of residence I, ppl.

$\mathrm{S}_{\mathrm{ij}}$ - cost of travel between areas i and $\mathrm{j}$, UAH

$\mathrm{D}_{\mathrm{i}}$ - average income of a resident of $\mathrm{i}$ zone, $\mathrm{km}$

Qz.z. $\mathrm{z}_{\mathrm{j}}$ - number of residents in the zone of residence I, ppl.

$\mathrm{S}_{\mathrm{ij}}$ - cost of travel between zones i and $\mathrm{j}$, UAH

$\mathrm{D}_{\mathrm{i}}$ - average income of a resident of i district. UAH.

in the gravity function of the workers of the city-forming enterprises are given in Tables 2-4.

The multiple regression model has the following form:

$$
\begin{aligned}
& d_{i j}^{y}=1.531 \frac{1}{t_{n_{i j}}}+0.0212\left(1 /\left(\frac{L_{r_{j}}}{L_{r s}}\right)\right)- \\
& -0.164\left(\log \left(\frac{Z_{z_{i}}}{Z_{r_{j}}}\right)\right)+0.043\left(\log \left(\frac{Q_{r . r_{j}}}{Q_{r . z_{i}}}\right)-,\right. \\
& -0.743 \sqrt{\left(\frac{S_{i j}}{D_{i}}\right)}+0.000000027 Q_{z . z_{i}}^{1,2}
\end{aligned}
$$


Table 5 The results of the evaluation of the model of changes of the gravity function of the workers of the city-forming enterprises

\begin{tabular}{|c|c|}
\hline Indicator & Value \\
\hline Student's t-test: $\quad$ tabular & 1.25 \\
\hline calculated & 125.24 \\
\hline Multiple correlation coefficient & 0.99 \\
\hline Average approximation error, \% & 13.4 \\
\hline
\end{tabular}

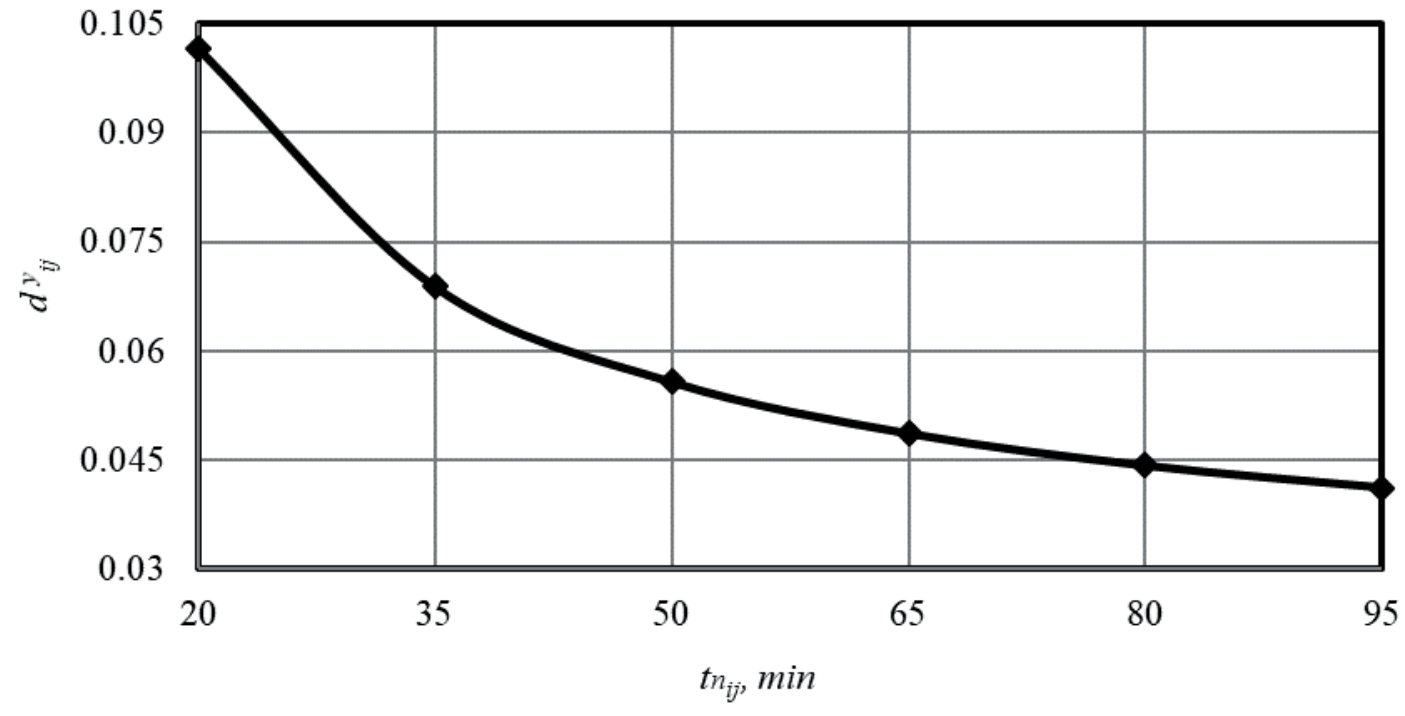

Figure 3 Graph of changes in the gravity function of employees of city-forming enterprises, depending on the travel time between zones $i$ and $j$

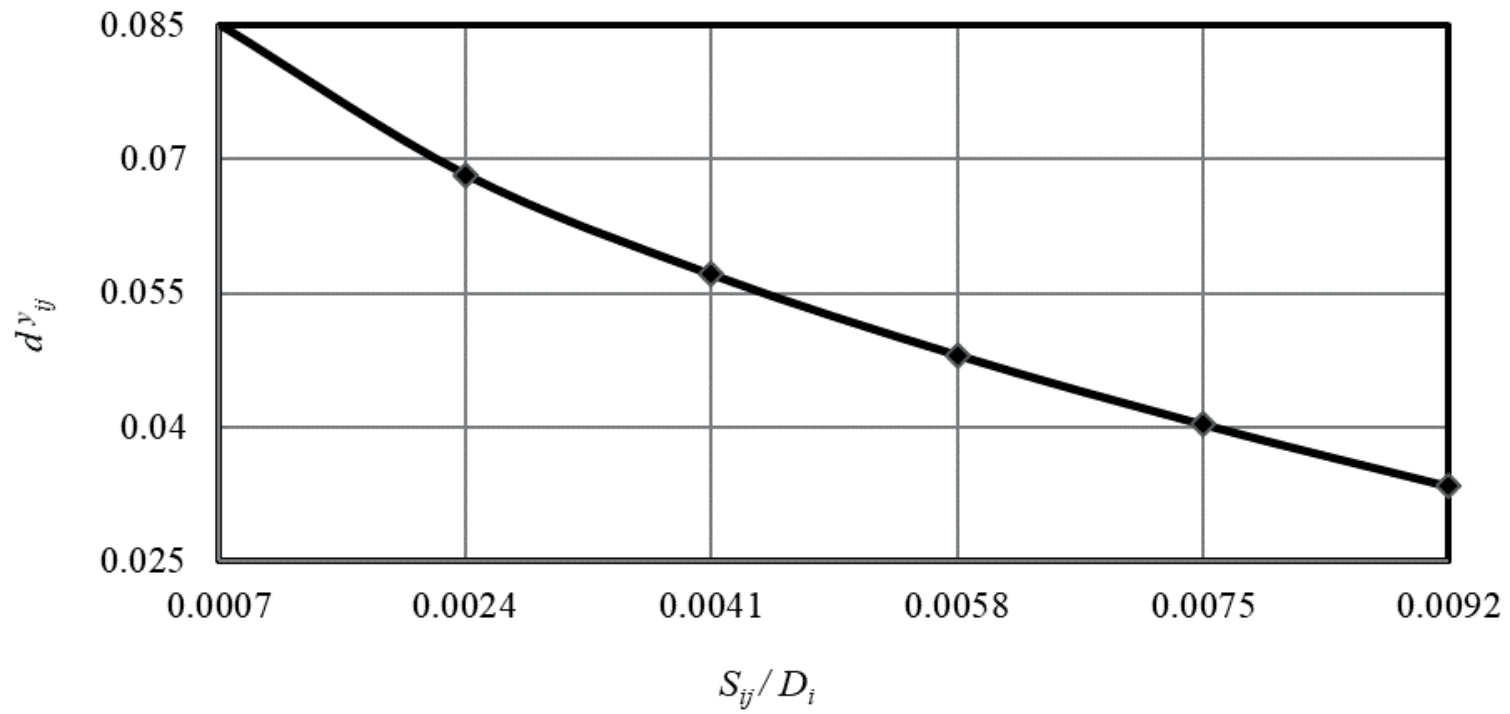

Figure 4 Graph of changes in the gravity function of employees of city-forming enterprises, depending on the ratio of the travel cost to the average income of residents of the zone of departure $i$

where:

$d^{y}{ }_{i j}$ - the gravity function of the workers of the city-forming enterprises between regions $i$ and $j$,

$t n_{i j}$ - travel time between zones $i$ and $j$,

$L r_{i}$ - distance from the zone of departure $i$ to the city center, Lrs - average distance from the zone to the center,
$Z z_{i}$ - the cost of one square meter of housing in the urban residence $I$,

$Z r_{j}$ - the cost of one square meter of housing in the work zone $j$,

Qr. $r_{j}$ - the number of places of employment in the work zone $j$. 


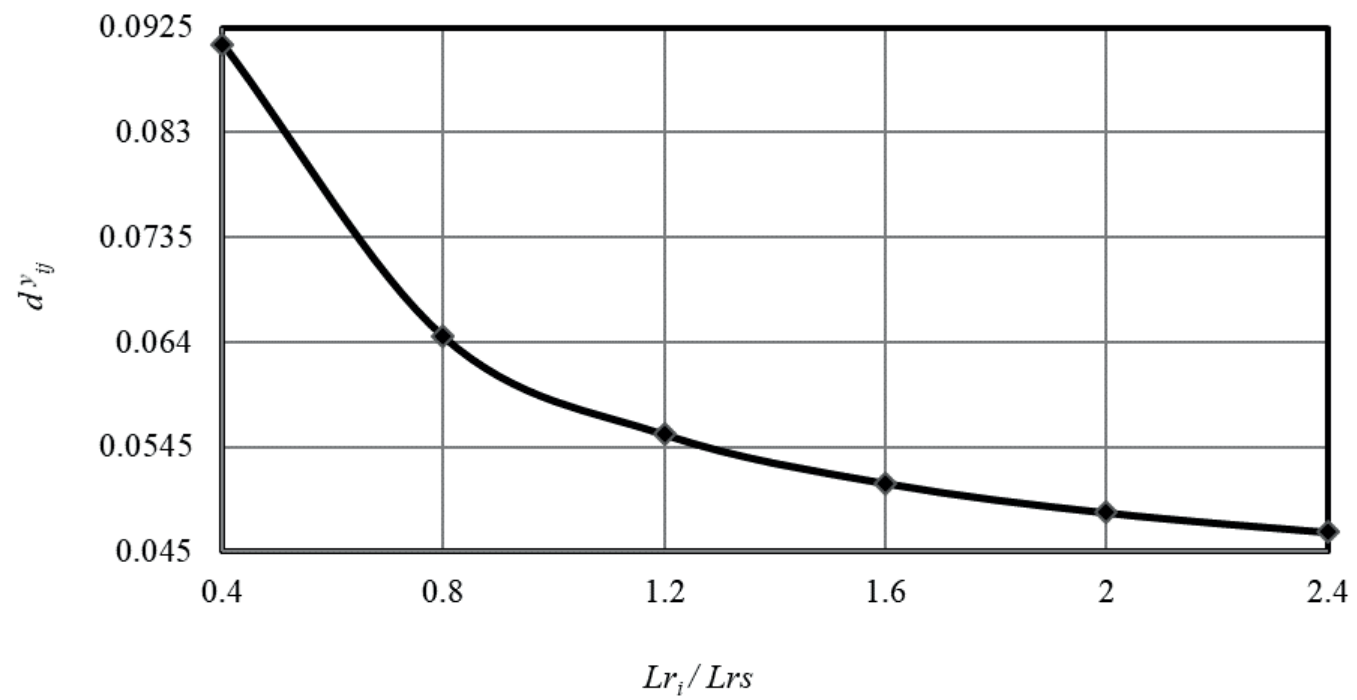

Figure 5 Graph of changes in the gravity function of employees of city-forming enterprises, depending on the ratio of remoteness of the zone of departure $i$ to the center to the average remoteness of the zones of the city from the center

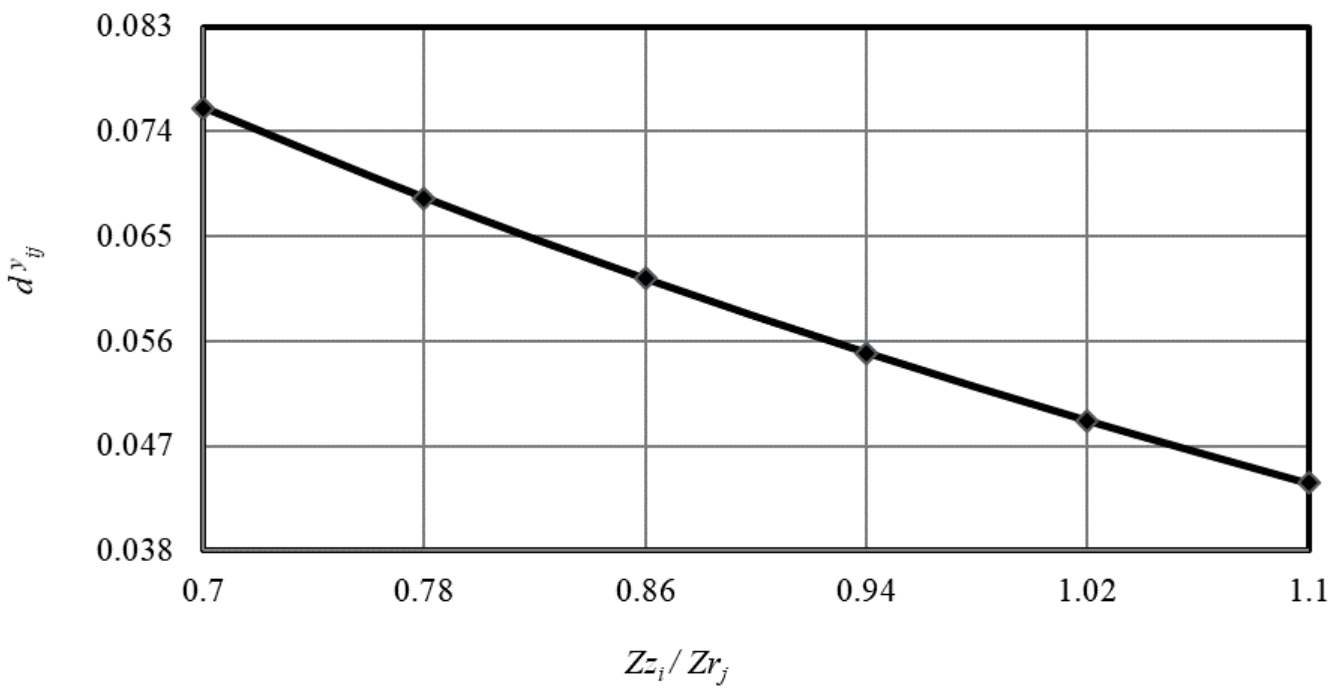

Figure 6 Graph of changes in the gravity function of workers of city-forming enterprises, depending on the ratio of the cost of one square meter of housing in the zone of residence $i$ to the cost of one square meter of housing in the zone of work $j$

After the development of the regression model, its statistical evaluation was carried out. The results of the calculations are given in Table 5 .

\section{Discussion}

The results of the research showed that in determining the patterns of change in the gravity function of the workers of the city-forming enterprises, of all the factors studied, only ten turned out to be significant, they form certain ratios. This is evidenced by the calculated value of Student's t-test, which is bigger than the table value. The closeness of the relationship between the dependent variable and the factors that influence its level was determined by the coefficient of multiple correlation. The value of the coefficient of multiple correlation indicates a high degree of closeness of the connection between the values of the gravity function and the selected factors. The assessment of the adequacy of the developed model was carried out in terms of the average approximation error. Its value corresponds to the permissible limits.

To analyze the changes in the gravity function of the workers of city-forming enterprises, graphs of its changes were constructed depending on the influence of each of the previously determined factors. When plotting the graphs, the value of one of the factors changed with the average values of others. The calculation results are shown in Figures 3-8.

Analysis of the received gravity function shows that the increase of the travel time between the areas of departure 


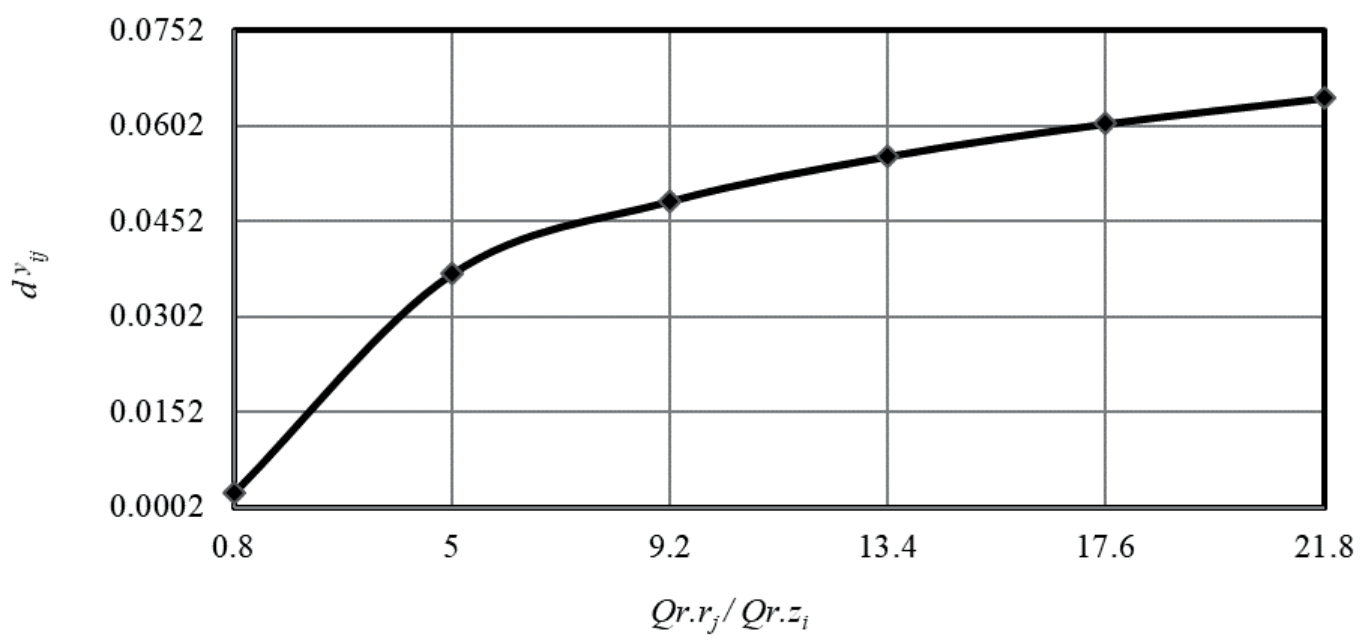

Figure 7 Graph of changes in the gravity function of workers of city-forming enterprises depending on the ratio of the number of places of application of labor in the industrial zone $j$ to the number of places of application of labor in the zone of residence $i$

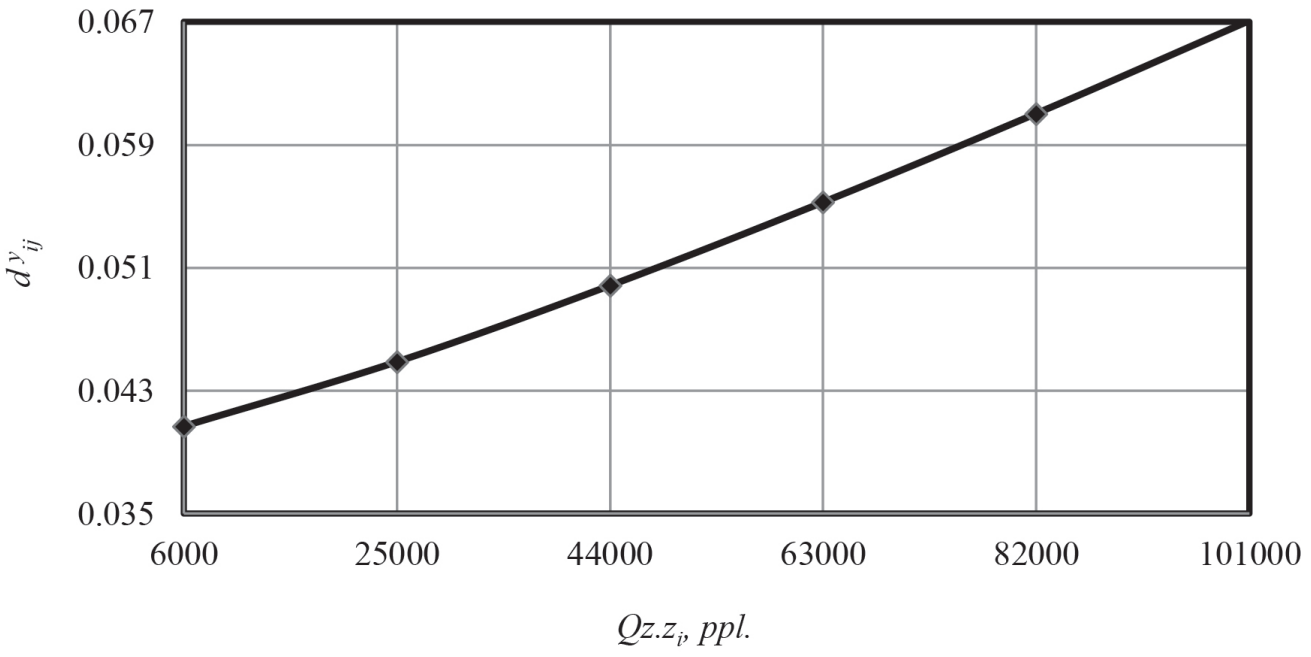

Figure 8 Graph of changes in the gravity function of employees of city-forming enterprises, depending on the number of residents in the zone of residence $i$

and arrival reduces the value of the gravity function. The more time it takes to travel, the fewer people will carry it. This conclusion is consistent with the results of previous studies.

An increase in the ratio of the travel cost to the average income of the residents of the area of departure leads to a decrease in the value of the gravity function. This is due to the fact that the higher is the travel cost in relation to income, the less people will make this trips. In this case, the route with a lower cost will be chosen.

The ratio of the remoteness of the area of departure from the city center to the average remoteness of the zone of the city from the center reduces the value of the gravity function. This is due to the fact that with an increase in the distance, possible transfers from one type of transport to another increase, the trip time and the cost of travel increase. All this causes a decrease in the attractiveness of potential travels from the area.
With the increase in the ratio of the cost of one square meter of housing in areas of residence and employment, the value of the gravity function decreases. This is due to the fact that employees of city-forming enterprises have more opportunities to purchase housing at the industrial zone. In addition, the cost of housing determines the prestige of the zones and residents may prefer to work in them.

With an increase in the ratio of the number of places of place of employment in the industrial area to the number place of employment in the zone of residence, the value of the gravity function increases. This is due to the fact that the likelihood of finding work in the area of gravity is higher than in the area of residence.

With the increase in the number of residents in the area of residence, the gravity function increases. With a large number of residents in the area of residence it is more difficult to find a job and residents will be forced to move to other parts of the city. 
Thus, we can conclude that the change in the gravity function of the workers of the city-forming enterprises is described with sufficient accuracy by the regression equation, in which the variables are factors that describe the urban structure, socio-economic factors and factors determining the parameters of zones of residence place of employment. As a result of the calculations, it is possible to conclude that it is acceptable to use the resulting model of the change of the gravity function of employees of the cityforming enterprises when designing the urban transport infrastructure.

\section{Conclusion}

The design of the urban transport infrastructure should be focused on creating a comfortable living environment and the development of territories. In accordance with this premise, it is necessary that decision makers in the sphere of design of urban transport infrastructure take into account the influence of the human factor on changes in the parameters of transport and passenger flows. The existing methods for determining the parameters of transport and passenger flows did not fully considered the patterns of settlement of urban residents, their subjective choice of method and ways of travel due to the lack of mathematical formalization of the gravity function, the patterns of choice of public and individual transport for the travel, as well as the distribution of the formed transport and passenger correspondence for the existing route and street-road network. The proposed gravity function of the workers of the city-forming enterprises is based on the parameters of the urban structure, socio-economic data and factors that determine the parameters of the zones of residence and place of employment. However, it should be noted that the given ranges for measuring the factors of the obtained model correspond to the input data for which they were obtained. As a result, they cannot be considered typical, since the parameters of cities and their transport systems may differ significantly. There is a need for further broader research of the influence of factors that determine the patterns of change in the gravity function of urban residents. The obtained data on the change in the gravity function of the workers of city-forming enterprises, depending on the parameters of the city, increase knowledge of the degree of influence of town-planning and socio-economic factors on the patterns of settlement of urban residents. The proposed gravity function will help municipal services to assess changes in the parameters of transport and passenger flows in the improvement of the urban transport infrastructure, as well as in the construction of new areas of residential development. This will allow the identification of such measures, which will provide the population with better living conditions to a greater extent. In the future, it is expected to continue research in the design of urban transport infrastructure, taking into account the human factor in determining its parameters. It is planned to determine the probability of choosing different types of travel: hiking, cycling, transport; the probability of choosing individual and public transport for transportation; the proportion of correspondence, which is realized by alternative ways of travel on an individual transport; determination of the proportion of passenger correspondence, which is realized by alternative routes of travel on public transport. The advantage of these researches is to take into account the individual characteristics of the urban inhabitants, namely gender, age and type of the nervous system.

\section{References}

[1] CERVERO, R. Transport infrastructure and the environment: sustainable mobility and urbanism [online]. Working Paper 2013-03. Berkeley: University of California, 2013 [accessed 2016-11-08]. Available from: http://iurd.berkeley.edu/wp/2013-03.pdf

[2] VICENTE, P., REIS, E. Ex-regular users of public transport: their reasons for leaving and returning. Journal of Public Transportation [online]. 2018, 21(2), p. 101-116. ISSN 1077-291X, eISSN 2375-0901. Available from: https//doi.org/10.5038/2375-0901.21.2.7

[3] BRANIS, M., HODAKOVA, D., CAPAYOVA, S., SCHLOSSER, T., GALKIN, A. Future of evaluating public transport services. $18^{\text {th }}$ International Multidisciplinary Scientific GeoConference SGEM: Surveying Geology \& Mining Ecology Management : proceedings. 2018. ISBN: 978-1-5108-7357-5, p. 565-571.

[4] SHIFTAN, Y., KAPLAN, S., HAKKERT, S. Scenario building as a tool for planning a sustainable transportation system. Transportation Research Part D: Transport and Environment [online]. 2003, 8(5), p. 323-342. ISSN 1361-9209, eISSN 1879-2340. Available from: https://doi.org/10.1016/S1361-9209(03)00020-8

[5] ALLSTROM, A., BARCELO, J., EKSTROM, J., GRUMERT, E., GUNDLEGARD, D., RYDERGREN, C. Traffic management for smart cities. In: Designing, developing, and facilitating smart cities. ANGELAKIS, V., TRAGOS, E., POHLS, H. C., KAPOVITS, A., BASSI, A. (eds.). Cham: Springer, 2017, p. 211-240. ISBN 978-3-319-44924-1.

[6] MUNDA, G. Social multi-criteria evaluation for urban sustainability policies. Land Use Policy [online]. 2006, 23(1), p. 86-94. ISSN 0264-8377, eISSN 1873-5754. Available from: https://doi.org/10.1016/j.landusepol.2004.08.012

[7] VUCHIC, V. R. Transportation for livable cities. Center for Urban Policy Research, 1999. ISBN 978-0882851617. 
[8] KHANSARI, N., MOSTASHARI, A., MANSOURI, M. Impacting sustainable behavior and planning in smart city. International Journal of Sustainable Land Use and Urban Planning [online]. 2014, 1(2), p. 46-61. ISSN $1927-8845$. Available from: https://doi.org/10.24102/ijslup.v1i2.365

[9] BANISTER, D. The sustainable mobility paradigm. Transport Policy [online]. 2008, 15(2), p. 73-80. ISSN 0967-070X, eISSN 1879-310X. Available from: https://doi.org/10.1016/j.tranpol.2007.10.005

[10] MILAN, L., KIN, B., VERLINDE, S., MACHARIS, C. Multi-actor multi-criteria analysis for sustainable city distribution: a new assessment framework. International Journal International Journal of Multicriteria Decision Making [online]. 2015, 5(4), p. 334-354. ISSN 2040-106X, eISSN 2040-1078. Available from: https://doi.org/10.1504/ijmcdm.2015.074088

[11] Great Britain Department for Transport - Design manual for roads and bridges: volume 12 Traffic appraisal of roads schemes, section 1 Traffic appraisal manual, Part 1 The application of traffic appraisal to trunk roads schemes, Section 2 Traffic apprasial advice [online]. 1999. Available from: http://www.standardsforhighways.co.uk/ha/standards/dmrb/vol12/section1.htm

[12] CHUMACHENKO, I. V., DAVIDICH, Y. A., GALKIN, A. S., DAVIDICH, N. V. Quality assessment of passenger transportation by urban transport while using various number of fixed-route transport facilities. Science \& Technique [online]. 2017, 16(5), p. 415-421. ISSN 2227-1031, eISSN 2414-0392. Available from: https://doi.org/10.21122/2227-1031-2017-16-5-415-421

[13] TOLEUEI, R., PSARRAS, S., PRINC, R. Origin-destination trip matrix development: conventional methods versus mobile phone data. Transportation Research Procedia [online]. 2017, 26, p. 39-52. ISSN 2352-1465. Available from: https://doi.org/10.1016/j.trpro.2017.07.007

[14] DRIL, N., GALKIN, A., BIBIK, N. Applying city marketing as a tool to support sustainable development in small cities: case study in Ukraine. Transportation Research Procedia [online]. 2016, 16, p. 46-53. ISSN 2352-1465. Available from: https://doi.org/10.1016/j.trpro.2016.11.006

[15] DOLYA, V. K. Pasazhirski perevezennya / Passenger transportation (in Ukranian). Harkiv: Fort, 2011. ISBN 978-966-8599-92-7.

[16] FEDOROV, V. P., BULYICHEVA, N. V., LOSIN, L. A., PAHOMOVA, O. M. Transportnaya sistema tsentra krupnogo goroda. Analiz s pomoschyu metodov matematicheskogo modelirovaniya / Transportation system of the center of a large city. Analysis using mathematical modeling methods (in Russian). Upravlenie Razvitiem Territorii / Territorial Development Management. 2009, 4, p. 18-25.

[17] SHAROV, M. I. Sovershenstvovanie metodi otsenki transportnogo sprosa na perevozki gorodskim pasazhirskim transportom / Improvement of methods of estimation of transport demand for transportation by urban passenger transport (in Russian). Author's abstract dissertation on the degree of Candidate Technical Sciences: 05.22.10. Irkutsk: ITTU, 2008.

[18] FURLeTTI, B., GABRIELli, L., GIANNOTTI, F., Milli, L., NANNI, M., PEDRESCHI, D., GAROFALO, G. Use of mobile phone data to estimate mobility flows. Measuring urban population and inter-city mobility using big data in an integrated approach. 47th Meeting of the Italian Statistical Society : proceedings. 2014. ISBN 978-88-8467-874-4, p. 1-11.

[19] GAVRILOV, E. V., LINNIK, I. E., SIROTA, V. M. Ergonomicheskoe obespechenie organizatsii dorozhnogo dvizheniya / Ergonomic support of the organization of road traffic (in Ukrainian). Kommunalnoe hozpodarstvo gorodov / Municipal economy of cities. 2004, 58, p. 163-169. ISSN 2522-1809.

[20] Novak, R. Management of the transport infrastructure development programme in the Czech Republic. Communications - Scientific Letters of the University of Zilina [online]. 2000, 2(4), p. 95-99. ISSN 1335-4205, eISSN 2585-7878. Available from: http://komunikacie.uniza.sk/index.php/communications/article/view/1081

[21] KLEBELSBERG, D. Verkehrspsychologie / Traffic psychology (in German) [online]. Berlin, Heidelberg, New York: Springer, 1982. ISBN 978-3-642-47507-8. Available from: https://doi.org/10.1007/978-3-642-47507-8

[22] GHYSEN, A. The origin and evolution of the nervous system. The International Journal of Developmental Biology. 2003, 47(7-8), p. 555-562. ISSN 0214-6282, eISSN 1696-3547.

[23] YAN, X., LEVILE, J., ZHAO, X. Integrating ridesourcing services with public transit: an evaluation of traveler responses combining revealed and stated preference data. Transportation Research Part C: Emerging Technologies [online]. 2019, 105, p. 683-696. ISSN 0968-090X, eISSN 1879-2359. Available from: https://doi.org/10.1016/j.trc.2018.07.029 